\title{
The Dynamic Econometric Analysis of Population Structure on Economic Growth in China
}

\author{
Haiying $\mathrm{Ma}^{1, \mathrm{a}^{*}}$ and Panpan Guo ${ }^{2, \mathrm{~b}}$ \\ ${ }^{1,2}$ School of Economics, Northwest University for Nationalities, Lanzhou (730124), P.R. China \\ axmahaiying8888@163.com, b1823482651@qq.com
}

\begin{abstract}
Keywords: Population structure; Economic growth; Johansen cointegration test; Vector error correction model
\end{abstract}

\begin{abstract}
This paper collects the data including Chinese population structure and per capita GDP from 1978 to 2006, and utilizes the econometric analysis methods of Johansen cointegration test and vector error correction model. Then this paper analyzes the effects of China's population structure on the economic growth and puts forward some suggestions by combining the current conditions and the results of the model.
\end{abstract}

\section{Introduction}

Many scholars pay attention to Chinese population problem for a long time. Chinese population has brought many problems because of its rapid growth and huge population base. After many years of efforts, Chinese population situation has put an end to the rapid population growth, and presents many new characteristics. Among them, the population structure is the prominent problem and it attracts our attention. Therefore, if we find the influence of population structure on economic growth, we can better understand the national conditions to develop the economy. This paper uses the date of structure of population and the per capita GDP in 1978-2006 to analysis the influence of population structure on economic growth in China.

Population development and economic growth are closely related with the process of mutual influence. Development economics holds that the development of population can not only promote the economic growth, but also hinder the development of economy. At the same time, economic development also has an important role in population development. In the end how to influence the population development and economic development, economic development how to effect on the population development, how the interaction mechanism between population development and economic development, these problems need to be quantitative research and scientific calculation, and on the basis of scientific decision-making is the urgent problem for us.

The domestic and foreign scholars studying the relationship between population and economy have touched the foreign scholars providing a good theoretical basis for the development of population and economy, such as the founder of Malthus, he systematically expounded the relationship between population and economy and pointed out that economic growth is likely to stimulate the population growth, while population growth will hinder economic growth, and population and economic growth is a negative feedback effect. Outstanding contributions to the economic theory of population such as Julian Simon, they argued that population growth is a positive impact on economic growth, there is a role in promoting. Luo(2000) et al, through the construction of economic growth model, further verify the important contribution of population quality to economic growth. In order to verify the relationship between population and economic growth, Wong and Fumitaka (2001) by using the measuring method, cointegration analysis method to analyze the relationship between population growth and economic growth is not simple, the research on Asian economies as the research object, analysis found that the Grainger two-way causal relationship between population and economic growth of the country Japan, South Korea and Thailand. For China, Singapore and Philippines, the population is found to be the Grainger cause of economic growth and vice versa. In Hong Kong and Malaysia, economic growth is found to be the cause of the population 
of Grainger rather than vice versa. For Taiwan and Indonesia, there is no evidence of a causal relationship between population and economic growth. In general, the population may have a positive or negative effect on economic growth, and economic growth will also affect population growth.

Domestic scholars focused on the relationship between population and economic growth involving in the following: the relationship between population growth and economic development. Wang(1999) used VAR model to examine the natural population growth rate and per capita GDP between the dynamic response, results show that there is a negative interaction between the long-term development of population and economy in China. Lai and Xiong (2003) choose the two variables of China's natural population growth rate and per capita GDP and use spatial linear regression model to reveal the relationship between population growth and economic growth. Guo(2006) posed on the development of the relationship between the age structure of population and economy in China. Zhang and Wang(2003), by using the Cobb Douglas production function model to analyze the relationship between economic development and changes in the age structure of the population. The empirical study on the relationship between urbanization and economic growth in Shanghai by using VAR model. the relationship between population mobility and economic development. Ma (2004) analyzed an empirical study on the relationship between population mobility and economic development by using grey correlation These results provide a good theoretical and empirical reference for us to continue to study the issue of population and economy. But it mainly presents the following features: one is the study of population with emphasis such as population growth, population age, city population, population flow and economic growth, the other relationship is less research on the population and economic research, there are many researches on one-way, such as the population development how to affect economic development, or economic development is how to influence the development of population. So this paper will be based on the characteristics of the main population such as population growth, population structure, population mobility and economic growth, in order to understand the interaction mechanism of the factors of population and economic growth.

\section{The Selection of Variables}

Population structure can be divided into three aspects to consider, they are respectively population age structure, population structure between urban and rural areas and population quality structure .This paper selects the proportion of labor population $\left(\mathrm{X}_{1} \%\right)$ to reflect the population age structure, and according to the UN standard, 15-64 year - old population are working age population. For urban and rural population structure can reflects the course of urbanization, so this paper selects the proportion of urban population $\left(\mathrm{X}_{2} \%\right)$ to reflect the population structure between urban and rural areas. Then this paper selects the average number of one college student in per ten thousand people $\left(\mathrm{X}_{3} \%\right)$ to reflect the cultural quality of the population structure, because it can reflect the development of higher education in China. Reflecting economic growth is per capita GDP (Y). This paper believes that per capita GDP eliminates the influence of population size and includes the most comprehensive content, so it could be reasonable to measure economic growth. At the same time, this paper makes the natural logarithm processing for index to remove heteroscedasticity and records for $\ln X_{1}, \ln X_{2}, \ln X_{3}, \ln Y$. In this paper the first order difference represents growth rate, recording for $d \ln X_{1}, d \ln X_{2}, d \ln X_{3}, d \ln Y$, and the result of second order difference records for $d d \ln \mathrm{X}_{1}, \mathrm{dd} \ln \mathrm{X}_{2}, \mathrm{dd} \ln \mathrm{X}_{3}$ and ddln $\mathrm{Y}$.

\section{Unit Root Test}

The most economic data are non-stationary data, and it cannot be directly used to build regression model. Index sequence must make a stationarity test in order to avoid the "Spurious regression" and reveal the true relationship between indexes. This paper uses the ADF test to do the stationarity test for index sequence which includes $\ln \mathrm{X}_{1}, \ln \mathrm{X}_{2}, \ln \mathrm{X}_{3}, \ln \mathrm{Y}$ and their difference sequences. Then we get the results such as table 1 by using E-views software. The results show that non-stationary series noted $\ln \mathrm{X}_{1}, \ln \mathrm{X}_{2}, \ln \mathrm{X}_{3}$ and $\ln \mathrm{Y}$ are second order list the whole sequence, namely $I(2)$. 
Table 1 The result of ADF test between population structure and economic growth index sequence

\begin{tabular}{|c|c|c|c|c|c|}
\hline variate & test form & ADF value & $\begin{array}{c}\text { critical value } \\
(1 \%)\end{array}$ & $\begin{array}{c}\text { critical value } \\
(5 \%)\end{array}$ & conclusion \\
\hline $\ln X 1$ & (C T 1) & -1.43 & -4.34 & -3.57 & not smooth \\
\hline $\ln X 2$ & (C T 2) & -2.84 & -4.36 & -3.59 & not smooth \\
\hline $\ln X 3$ & (C T 1) & -0.57 & -4.34 & -3.57 & not smooth \\
\hline $\ln Y$ & (C T 1) & -3.05 & -4.34 & -3.57 & not smooth \\
\hline $\mathrm{d} \ln \mathrm{X} 1$ & $\left(\begin{array}{lll}\mathrm{C} & 0 & 1\end{array}\right)$ & -2.39 & -3.71 & -2.98 & not smooth \\
\hline $\mathrm{d} \ln \mathrm{X} 2$ & $\left(\begin{array}{lll}\mathrm{C} & 0 & 1\end{array}\right)$ & -1.78 & -3.71 & -2.98 & not smooth \\
\hline $\mathrm{d} \ln \mathrm{X} 3$ & $\left(\begin{array}{lll}\mathrm{C} & 0 & 1\end{array}\right)$ & -2.27 & -3.71 & -2.98 & not smooth \\
\hline$d \ln Y$ & $\left(\begin{array}{lll}\mathrm{C} & 0 & 1\end{array}\right)$ & -3.06 & -3.17 & -2.98 & not smooth \\
\hline $\mathrm{dd} \ln \mathrm{X} 1$ & $\left(\begin{array}{lll}0 & 0 & 2\end{array}\right)$ & -4.66 & -2.66 & -1.96 & smooth \\
\hline $\mathrm{dd} \ln \mathrm{X} 2$ & $\left(\begin{array}{lll}0 & 0 & 1\end{array}\right)$ & -5.36 & -2.66 & -1.96 & smooth \\
\hline $\mathrm{dd} \ln \mathrm{X} 3$ & $\left(\begin{array}{lll}0 & 0 & 2\end{array}\right)$ & -4.79 & -2.66 & -1.96 & smooth \\
\hline $\mathrm{dd} \ln \mathrm{Y}$ & $\left(\begin{array}{lll}0 & 0 & 1\end{array}\right)$ & -4.53 & -2.66 & -1.96 & smooth \\
\hline
\end{tabular}

Note: the $\mathrm{C}, \mathrm{T}, \mathrm{L}$ in the test form $(\mathrm{C} \mathrm{T} \mathrm{L})$ respectively on behalf of constant term, time trend item, lag order in the model. The choice of lag order is based on Schwartz information criterion (SC).

\section{The Test of Cointegration Relationship and Vector Error Correction Model}

Cointegration and Cointegration Test. If two or more than two non-stationary time series are stationary through a linear combination, we can say that there is a cointegration relationship between non-stationary time series. There exists a long-term equilibrium relationship between economic phenomena. Through unit root test, we know that time series are smooth. Then, by using Johansen test, this paper makes cointegration test for population structure and economic growth index sequence. The results are as follows:

Table 2 Johansen test between population structure and economic growth index sequence

\begin{tabular}{ccccc}
\hline $\begin{array}{c}\text { characteristic } \\
\text { value }\end{array}$ & likelihood ratio & $\begin{array}{c}\text { the critical value } \\
(1 \%)\end{array}$ & $\begin{array}{c}\text { the critical value } \\
(5 \%)\end{array}$ & $\begin{array}{c}\text { the number of } \\
\text { cointegration }\end{array}$ \\
\hline 0.81 & 0.46 & 0.04 & 0.27 & 71.76 \\
26.32 & 9.5 & 47.21 & 0.99 & 29.68 \\
15.41 & 3.76 & 35.65 & 54.46 & 20.04 \\
6.65 & zero** & up to 2 & up to 1 & up to 3 \\
\hline
\end{tabular}

Note: The sign of ** means if the critical value under the $1 \%$ threshold we can refuse to accept the original hypothesis and we could think that the original hypothesis does not exist cointegration relationship.

The table 2 shows that there exists the only cointegration relationship between four indicators of the population structure and economic growth. The cointegration equation is $\ln Y=27.48 * \ln X 1-3.42$ $* \ln \mathrm{X} 2+0.76 * \ln \mathrm{X} 3-98.65$, Which states that there exists a long-term equilibrium relationship between 
four time series of China's population structure and economic growth. This dynamic equilibrium relationship states that between population structure and economic growth has certain coordination since reform and opening up in China.

Vector Error Correction Model. On the basis of the cointegration test, this paper establishes the vector error correction model about sequence $\ln \mathrm{X} 1, \ln \mathrm{X} 2, \ln \mathrm{X} 3$ and $\ln \mathrm{Y}$ by using the E-Views software. This paper is to explore the influence of population structure on economic growth, so it only give this error correction model which takes dlnYt as dependent variable and takes $\operatorname{dln} Y_{t-1}, d \ln X 1_{t-1}$, $\mathrm{d} \ln \mathrm{X} 2_{\mathrm{t}-1}, \mathrm{~d} \ln \mathrm{X} 3_{\mathrm{t}-1}$ as explanatory variables. The error correction model is:

$\mathrm{d} \ln \mathrm{Y}_{\mathrm{t}}=0.5879 * \mathrm{~d} \ln \mathrm{Y}_{\mathrm{t}-1}-4.0749 * \mathrm{~d} \ln \mathrm{X}_{1 \mathrm{t}-1}+1.2242 * \mathrm{~d} \ln \mathrm{X}_{2 \mathrm{t}-1}-0.0204 * \mathrm{~d} \ln \mathrm{X}_{3 \mathrm{t}-1}-0.1537 * v e c m t-1+0.0455$

\section{Conclusions}

This paper obtains the cointegration equation and error correction model, so we can get some conclusions and give corresponding suggestions.

In the long run, the proportion of labor population has a positive effect on economic growth, and its effect is greater than the other two factors' driving effect on economic growth. Labor population growth and economic growth present reverse movement in the short term, which explains Chinese one-child policy not only greatly controls the growth of China's total population, but also provides a significant source for economic growth by early wining the age structure advantage.

In the short term, the acceleration of urbanization in China has a positive effect on economic growth. However, China's urbanization has brought certain negative impact on economic growth in the long run. The formulation and implementation of Chinese urbanization strategy seem to be more expedient for solving contradictions, which is lack of integrity and forward-looking. The heavy traffic and fragile environmental protection effect the development of the city, and they have made the subsequent development of this city at a disadvantage position. Therefore, China should stick to the sustainable development and establish reasonable urban system. Chinese government should consider the town's present development situation, through a reasonable adjustment of city layout and function integration, effort to build a harmonious system of urbanization. At the same time, China should establish the development direction of urban system by considering the future development of cities.

In the long run, the development of Chinese higher education has obviously positive effect to our country's economic growth. Therefore, China should increase the education investment and improve teaching quality. Then China can promote labor productivity and the progress of science and technology by improving human capital to enhance the long-term effects of the higher education to economic growth. In the short term, the development of Chinese higher education has a negative effect on economic growth, which proving that the returns of Chinese higher education are very low. The factors which coursing such phenomenon may be the low level balance between higher education and economic development, excessive higher education and intelligence outflow, etc. So it is necessary to have a deep study about the theory of the development of higher education scale.

\section{References}

[1] Liu jia Shu, The empirical analysis of relationship between population structure and economic growth in our country, Journal of Anhui university of technology. 2 (2007)229-232

[2] Geng Dai, A harmonious society under the cointegration model of social economy and population, Science and Technology Information. 7(2007)22-23

[3] Yi Danfeng, Data analysis and E-View application, The first edition. Beijing: China Statistics Press. 12(2005)135-185

[4] Liu lijie, population as long-run economic growth factors: an empirical investigation for Greece using causality analysis, Regional Economics. 5 (2014) 105-116.

[5] Hou Huating, The Development Strategy of Gansu rural-urban migration, Journal of Gansu Nationalities University. 5(2012)66-79. 
[6] Xiao Lin, the Relationship between population migration and GDP Growth in China, Research in World Economy. 6 (2013)112-130.

[7] Blake A., Sinclair T, population and globalization: economic impact in Indonesia, Annals of Labour Research. 24 (2008) 613-627.

[8] Tian Li-fa, Zhou Jian, Zhang Yan-li, foreign exchange income and economic growth in China: A panel cointegration approach, International Conference on Management Science and Engineering. 8(2010) 950-961.

[9] Ballaguer, J. \& Cantavella-Jorda, M, migration of labor as a long-run economic growth factor: the Spanish case. Applied Economics. 34(2002)877-884.

[10] Bhagwati, J. and Srinivasan, T, Trade policy and development, International Economic Policy: Theory and evidence. 12(1979)6-35. 